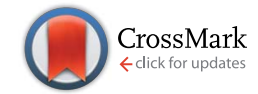

Cite this: RSC Adv., 2017, 7, 5715
Received 9th October 2016 Accepted 2nd December 2016

DOI: 10.1039/c6ra24961b

www.rsc.org/advances

\section{Phase behavior of a binary lipid system containing long- and short-chain phosphatidylcholines $\uparrow$}

\begin{abstract}
Hai-Yuan Sun, ${ }^{a}$ Fu-Gen Wu, ${ }^{b}$ Zhi-Hong Li, ${ }^{c}$ Geng Deng, ${ }^{a}$ Yu Zhou ${ }^{\text {ad }}$ and Zhi-Wu Yu*a
Bilayered micelles, or so-called bicelles, are generally made of long- and short-chain lipids. They are extensively used as model membranes to study the structure of membrane-associated peptides or proteins and their interactions with membranes. However, the phase behavior of lipid mixtures composed of longand short-chain lipids, especially at low temperatures, is still not very clear. In this work, the most commonly used long-chain lipid, 1,2-dipalmitoyl-sn-glycero-3-phosphocholine (DPPC), and a short-chain lipid, 1,2-dioctanoyl-sn-glycero-3-phosphocholine (diC8PC), were selected as a bicellar model to study their phase behavior. Over the whole range of DPPC/diC8PC molar ratios (q) studied in this work, a lamellar crystalline phase $\left(L_{c^{\prime}}\right)$ enriched in DPPC was found to be the most stable phase at $5{ }^{\circ} \mathrm{C}$, together with a diC8PC-enriched micelle phase. Interestingly, a metastable phase, named the $U$ phase in this work, was observed in the mixtures with a DPPC/diC8PC molar ratio between 1 and 4 . The metastable $U$ phase was found to be lacking in long-range order in the direction of the bilayer surface normal, but bearing a different "crystalline phase-like" hydrocarbon chain packing mode, in comparison with the lamellar crystalline phase. The kinetic properties of the $U$ phase were also studied in detail, and it was found that the phase acts as a precursor phase in the process of forming the most stable crystalline phase. This work deepens our understanding of lipid crystallization behavior, and is also a step forward towards a more detailed picture of the phase behavior of lipid mixtures composed of long- and short-chain lipids.
\end{abstract}

\section{Introduction}

Bicelles are model membranes composed of long- and shortchain lipids, which are spatially separated in bilayer and "rim" or pore portions, respectively. ${ }^{1-3}$ They have gained much attention since the 1990 s due to their great potential in the study of membrane proteins. The planar bilayer region enriched in the long-chain lipids provides a favorable environment to study membrane proteins using various techniques, such as nuclear magnetic resonance (NMR), ${ }^{4-11}$ X-ray crystallography, ${ }^{12-16}$ and spectroscopy techniques. ${ }^{17-21}$ Bicelles can also be used as delivery vehicles for membrane proteins or drugs, ${ }^{22,23}$ or as templates for the synthesis of platinum nanowheels. ${ }^{\mathbf{2 4 , 2 5}}$

${ }^{a}$ Key Laboratory of Bioorganic Phosphorous Chemistry and Chemical Biology (Ministry of Education), Department of Chemistry, Tsinghua University, Beijing 100084, P. R. China. E-mail: yuzhw@tsinghua.edu.cn

${ }^{b}$ State Key Laboratory of Bioelectronics, School of Biological Science and Medical Engineering, Southeast University, Nanjing 210096, P. R. China

'Beijing Synchrotron Radiation Facility, Institute of High Energy Physics, Chinese Academy of Sciences, Beijing 100049, P. R. China

${ }^{d}$ School of Chemistry and Chemical Engineering, Qingdao University, Qingdao 266071, P. R. China

$\dagger$ Electronic supplementary information (ESI) available: DSC result of DPPC-diC8PC binary mixture with $q=1$ using the same protocol as in the $i n$ situ SAXS experiment. See DOI: 10.1039/c6ra24961b
When applied to the crystallization of membrane proteins, bicelles composed of long- and short-chain lipids usually go through a mixing process with the membrane protein solution on ice, followed by a membrane protein crystal growth period at a higher temperature $\left(\right.$ e.g. $5{ }^{\circ} \mathrm{C}, 20^{\circ} \mathrm{C}$, or $\left.37^{\circ} \mathrm{C}\right) .{ }^{12,13,15,26}$ Besides, the storage of a bicelle solution usually requires isothermal incubation at a specific low temperature, such as $4{ }^{\circ} \mathrm{C}$, in a refrigerator. ${ }^{27}$ The detailed phase behavior upon $T$-jump and low-temperature incubation is a key point for understanding the mechanism by which the nucleation and crystal growth of membrane proteins occur. Thus, it is of vital importance to learn the phase behavior of bicellar systems composed of longand short-chain lipids.

The present work is also a continuation of our efforts in understanding the complex phase behavior of lipids and lipid mixtures, especially the formation mechanisms of crystalline phases in lipid systems. ${ }^{28-34}$ In 1980, Chen et al. demonstrated that under prolonged incubation at around $0{ }^{\circ} \mathrm{C}$, PCs with hydrocarbon chains of 16-18 carbon atoms would convert from the gel phase to a so-called subgel phase $\left(\mathrm{L}_{\mathrm{c}}\right.$ or $\left.\mathrm{L}_{\mathrm{c}^{\prime}}\right)$, which is actually a crystalline phase..$^{35}$ The structure and formation of the crystalline phase of PCs have been the subject of numerous studies since then. ${ }^{36-45}$ As research continues, people found that the formation process of the subgel phase of lipids is far more complicated than they originally thought. ${ }^{36-45}$ The complexity of the subgel phase formation arises from the interplay between kinetic and 
thermodynamic factors. Tristram-Nagle et al. proved that the crystallization process of fully hydrated DPPC from the gel phase to the subgel phase follows a nucleation-growth mechanism, using X-ray diffraction data and a designed $T$-jump protocol. ${ }^{46}$ Lewis et al. systematically studied the crystallization process of $n$ saturated PCs with different chain lengths using FTIR spectroscopy. ${ }^{40}$ According to their work, $n$-saturated PCs $(n=10-18)$ will first transform into a metastable crystalline phase $\left(\mathrm{L}_{\mathrm{c}_{1}}\right)$ and finally change to the most stable crystalline phase, through a series of intermediates, depending on the tail length. Tenchov et al. studied various types of lipids, including PC, phosphatidylethanolamine (PE), and phosphatidylglycerol (PG), and summarized some general features of the metastable phases occurring between the gel and the subgel phases, and two types of precursor phases were proposed: the $\mathrm{L}_{\mathrm{R}_{1}}$ phase and the SGII phase. ${ }^{44}$ In the former, the hydrocarbon chains are perpendicular to the bilayer plane and are arranged in an orthorhombic lattice of four-nearestneighbor type, similar to the metastable rotator phases found in long-chain normal alkanes upon crystallization. ${ }^{47,48}$ In the latter, the hydrocarbon chains are tilted to the bilayer plane and arranged in an orthorhombic lattice of two-nearest-neighbor type.

In the present work, by using two saturated PC lipids that differ only in the carbon number of the acyl tails, 1,2-dipalmitoyl-sn-glycero-3-phosphocholine (DPPC) and 1,2-dioctanoyl-snglycero-3-phosphocholine (diC8PC), we designed a system to study the phase behavior of lipid mixtures composed of longand short-chain lipids, using both an isothermal protocol and a $T$-jump protocol. The influence of the molecular ratio of DPPC/diC8PC, $q$, was studied and we found that mixtures with lower $q$ values favored the formation of a new metastable phase, which transforms into the most stable $\mathrm{L}_{\mathrm{c}^{\prime}}$ phase upon a longenough incubation at $5{ }^{\circ} \mathrm{C}$.

\section{Experimental section}

\subsection{Sample preparation}

DPPC and diC8PC were purchased from Avanti Polar Lipids (Birmingham, AL, USA). Weighed amounts of DPPC and diC8PC were premixed in chloroform, and then the solvent was evaporated under a stream of nitrogen. The mixtures were then kept in a vacuum for more than $12 \mathrm{~h}$ to remove the residual solvent. Double-deionized $\mathrm{H}_{2} \mathrm{O}$ with a resistivity of $18.2 \mathrm{M} \Omega \mathrm{cm}$ or $\mathrm{D}_{2} \mathrm{O}$ (99.9\% deuterium, from Cambridge Isotopes, USA) was then added to the obtained mixtures. The lipid/water weight ratio was fixed at $1 / 3$. Homogeneous lipid dispersions were prepared by vortexing the mixtures at $60{ }^{\circ} \mathrm{C}$ for $20 \mathrm{~min}$, and were then subject to 4 repeated thermal cycles between $-40{ }^{\circ} \mathrm{C}$ and $60{ }^{\circ} \mathrm{C}$. Six compositions of the lipid mixtures were examined. The molar percentages of diC8PC over the total lipids were $5 \%, 10 \%$, $20 \%, 25 \%, 41 \%$, and $50 \%$. In the area of bicelles, the molar ratio $(q)$ is a more frequently used parameter, and the respective ratios of DPPC/diC8PC are 19, 9, 4, 3, 1.44, and 1.

\subsection{Isothermal protocol and $T$-jump protocol}

Lipid samples were first heated to $60{ }^{\circ} \mathrm{C}$ to remove their thermal history. After that, the following protocols, unless otherwise specified, were used. For the isothermal protocol, samples were incubated at $5{ }^{\circ} \mathrm{C}$ for $30 \mathrm{~d}$. For the $T$-jump protocol, the samples were first incubated at $-20{ }^{\circ} \mathrm{C}$ for 24 hours and then cooled to $5{ }^{\circ} \mathrm{C}$ for 4 days of incubation. Their kinetic properties were studied by changing the incubation time at specified temperatures, which can be found in the related sections and figures.

\subsection{DSC}

Calorimetric data were obtained using a differential scanning calorimeter, DSC821 ${ }^{\mathrm{e}}$ (Mettler-Toledo Co., Switzerland), equipped with a mechanical cooling system. A high-sensitivity sensor HSS7 was adapted for the system.

\subsection{Synchrotron $X$-ray scattering}

Small-angle X-ray scattering (SAXS) and wide-angle X-ray scattering (WAXS) experiments were performed at the Beamline 1W2A of the Beijing Synchrotron Radiation Facility (BSRF) $(\lambda=$ $1.54 \AA$ A). For simultaneous SAXS-WAXS measurements, a Pilatus $1 \mathrm{MF}$ detector $(169 \mathrm{~mm} \times 179 \mathrm{~mm})$ and a Mar165 CCD detector $(\Phi=165 \mathrm{~mm})$ were used. A standard silver behenate sample and a standard carbon fiber sample were used for the calibration of the two detectors. A Linkam thermal stage (Linkam Scientific Instruments, UK) was used for temperature control $\left( \pm 0.1{ }^{\circ} \mathrm{C}\right)$. The $2 \mathrm{D}$ patterns were converted to $1 \mathrm{D}$ data using the program Fit2D, and the dead data collected by the Pilatus 1MF detector were recovered using a program developed by Zhihong $\mathrm{Li}^{\mathbf{4 9 , 5 0}}$

\subsection{FTIR spectroscopy}

FTIR spectra were recorded using a Nicolet 5700 Fourier transform infrared spectrometer with an MCT detector in the range $4000-1000 \mathrm{~cm}^{-1}$. The spectral resolution is $2 \mathrm{~cm}^{-1}$ and the zero filling factor is 2 . Samples were coated onto the inner surfaces of a pair of $\mathrm{CaF}_{2}$ windows, and the temperature was controlled with the Linkam thermal stage.

\section{Results and discussion}

\subsection{Phase behavior of DPPC-diC8PC system using two protocols}

The phase behavior of various DPPC-diC8PC mixtures, determined by the $T$-jump protocol and isothermal protocol, was first examined with a DSC technique, and the results of the first heating scans are shown in Fig. 1. The phase states of the mixtures at different temperatures were identified with the help of SAXS and WAXS, which will be presented later. For DPPC, both protocols give the same result, with the DSC heating curve showing sequentially the sub-, pre-, and main transitions upon increasing the temperature at temperatures of $23{ }^{\circ} \mathrm{C}, 38^{\circ} \mathrm{C}$, and $42{ }^{\circ} \mathrm{C}$, respectively. The presence of the sub-transition suggests that after treatment with both protocols (the incubation time of the isothermal protocol for DPPC was $15 \mathrm{~d}$ ), DPPC is at the subgel $\left(\mathrm{L}_{\mathrm{c}^{\prime}}\right)$ phase, which is consistent with previous work. ${ }^{32,48}$ However, mixtures containing diC8PC show different thermotropic phase behavior, depending on the values of $q$, as can be seen in Fig. 1. On the one hand, for all the mixtures containing diC8PC, the DSC curves show the disappearance of the pre- 
A
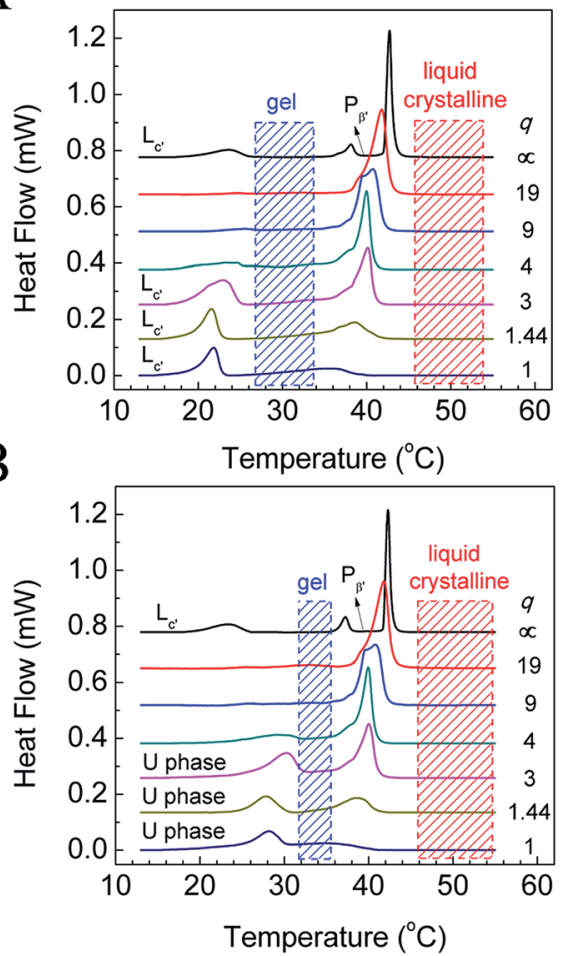

Fig. 1 DSC results for DPPC-diC8PC binary mixtures dispersed in water after treatment with (A) $T$-jump protocol and (B) isothermal protocol. The corresponding $q$ values are labeled on the right side of each curve, and the phase states at respective temperature ranges are labeled above the curves.

transition peak at around $38^{\circ} \mathrm{C}$ compared to DPPC, which is the phase transition from the lamellar gel phase $\left(\mathrm{L}_{\beta^{\prime}}\right)$ to the rippled gel phase $\left(\mathrm{P}_{\beta^{\prime}}\right) .^{32}$ The disappearance of the pre-transition of DPPC is also seen in other systems when another component, for example, DOPA, is added..$^{34}$ On the other hand, there are differences in the DSC curves between the mixtures containing diC8PC, depending on the $q$ values. Accordingly, the samples containing diC8PC are classified into 2 groups: mixtures with high $q(19,9$, and 4$)$ and low $q(3,1.44$, and 1$)$ values. When the mixtures were treated with the $T$-jump protocol, the DSC curves of the high- $q$ mixtures exhibit no or little endothermic peaks in the range $15{ }^{\circ} \mathrm{C}$ to $25{ }^{\circ} \mathrm{C}$ (Fig. $1 \mathrm{~A}$ ), indicating that no or little $\mathrm{L}_{\mathrm{c}^{\prime}}$ phase is formed. But for the low- $q$ mixtures, after treatment with the $T$-jump protocol, the DSC curves exhibit significant endothermic peaks in this temperature range, indicating that the mixtures form a certain amount of $\mathrm{L}_{\mathrm{c}^{\prime}}$ phase domains. For the isothermal protocol (Fig. 1B), the high- $q$ mixtures show no or small peaks, except for the main transition over the whole temperature range displayed, which is the same as for the case with the $T$-jump protocol. Conversely, the DSC curves of low- $q$ mixtures give peaks in the temperature range $25-35{ }^{\circ} \mathrm{C}$, higher than the sub-transition, suggesting different phase behavior. The new phase, which has not been reported to the best of our knowledge, is named the $\mathrm{U}$ phase in this work. The features and formation kinetics of these two phases will be discussed later.
To identify the phase states of the mixtures, we performed SAXS and WAXS experiments. Since high- $q$ mixtures do not show a large difference under the two protocols, we focused mainly on two mixtures with $q=1.44$ and 1 , and pure DPPC. The results at selected temperatures are shown in Fig. 2. For DPPC, the phases at $5{ }^{\circ} \mathrm{C}, 30^{\circ} \mathrm{C}$, and $50{ }^{\circ} \mathrm{C}$ are identified as the lamellar crystalline phase $\left(\mathrm{L}_{\mathrm{c}^{\prime}}\right)$, the lamellar gel phase $\left(\mathrm{L}_{\beta^{\prime}}\right)$, and the lamellar liquid crystalline phase $\left(\mathrm{L}_{\alpha}\right)$, respectively. In the SAXS region, the reciprocal spacings $(s)$ at the scattering maxima show a ratio of $1: 2: 3$ for all the three phase states, indicating that these phases are lamellar. The repeat distances of these structures are evaluated as $6.01 \mathrm{~nm}\left(5{ }^{\circ} \mathrm{C}\right), 6.36 \mathrm{~nm}$ $\left(30{ }^{\circ} \mathrm{C}\right)$, and $6.7 \mathrm{~nm}\left(50{ }^{\circ} \mathrm{C}\right)$, respectively, in good agreement with previous works. ${ }^{32,51-53}$ In the WAXS region, several peaks were observed in the crystalline phase at $2.26,2.37$, and 2.56 $\mathrm{nm}^{-1}$, which are consistent with the literature..$^{32,53,54}$ These peaks in the WAXS region indicate that the hydrocarbon chains of the lipid in the crystalline phase are highly ordered and, according to previous publications, they are in a triclinic lattice. ${ }^{52}$ For the gel phase of DPPC, the peak at $2.37 \mathrm{~nm}^{-1}$ with a shoulder at around $2.44 \mathrm{~nm}^{-1}$ reveals that the hydrocarbon chains are in a distorted hexagonal lattice. ${ }^{55-57}$ The corresponding spacings are 0.42 and $0.41 \mathrm{~nm}$. For the liquid crystalline phase, the WAXS region shows a broad peak centered at $s=2.20 \mathrm{~nm}^{-1}$ (or $d=0.46 \mathrm{~nm}$ ), which indicates that the hydrocarbon chains are loosely packed..$^{32,33}$ For the mixtures with $q=1.44$ and 1 , the scattering profiles at $30{ }^{\circ} \mathrm{C}$ indicate that they are in a non-tilted lamellar-gel state, typified with lamellar SAXS patterns and a symmetric WAXS peak at 2.45 $\mathrm{nm}^{-1}$. The spacing calculated from the WAXS data is $0.41 \mathrm{~nm}$, which is a little shorter than the spacing in the $\mathrm{L}_{\beta^{\prime}}$ phase of pure DPPC $(0.42 \mathrm{~nm})$, suggesting a more tightly packed mode of the hydrocarbon chains in the former. In the SAXS region, a lamellar structural feature can be clearly seen with a repeat distance of $5.87 \mathrm{~nm}$, markedly shorter than that of the $\mathrm{L}_{\beta^{\prime}}$ phase of pure DPPC, which is explained by interdigitation of the chains of diC8PC and DPPC. Thus, the gel phase of the mixtures with $q=1.44$ and 1 is actually an interdigitated lamellar gel phase $\left(\mathrm{L}_{\beta} \mathrm{I}\right)$, which is reasonable for the phospholipid mixtures containing a long-tail component and a short-tail component. The stable phase at low temperature of the two mixtures is the lamellar crystalline phase $\left(\mathrm{L}_{\mathrm{c}^{\prime}}\right)$, as evidenced by the SAXS and WAXS data. In the SAXS region, the $s$ values of the scattering peaks are $0.153,0.291$, and 0.444 $\mathrm{nm}^{-1}$, close to a ratio of $1: 2: 3$, indicating that the $\mathrm{L}_{\mathrm{c}^{\prime}}$ phase is a lamellar structure with a $d$ value of $6.54 \mathrm{~nm}, 0.54 \mathrm{~nm}$ longer than that of the crystalline phase of DPPC. The increase in the repeat distance may be attributed to the decrease in the tilt angle, which is $34^{\circ}$ in the crystalline phase of DPPC. ${ }^{\mathbf{4 4 , 5 1 , 5 8}}$ In the WAXS region, the peaks are similar to those for the crystalline phase of DPPC. The similarity implies that the hydrocarbon chains are in a triclinic lattice, which is also proven by the FTIR results discussed in the next section.

To characterize the newly identified $U$ phase, we have tried to prepare samples as pure as possible with only this phase state. Clearly, as shown in Fig. 2, a broad peak is seen in the SAXS region, indicating the lack of long-range order in the 


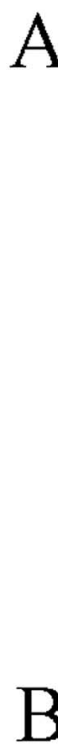

B
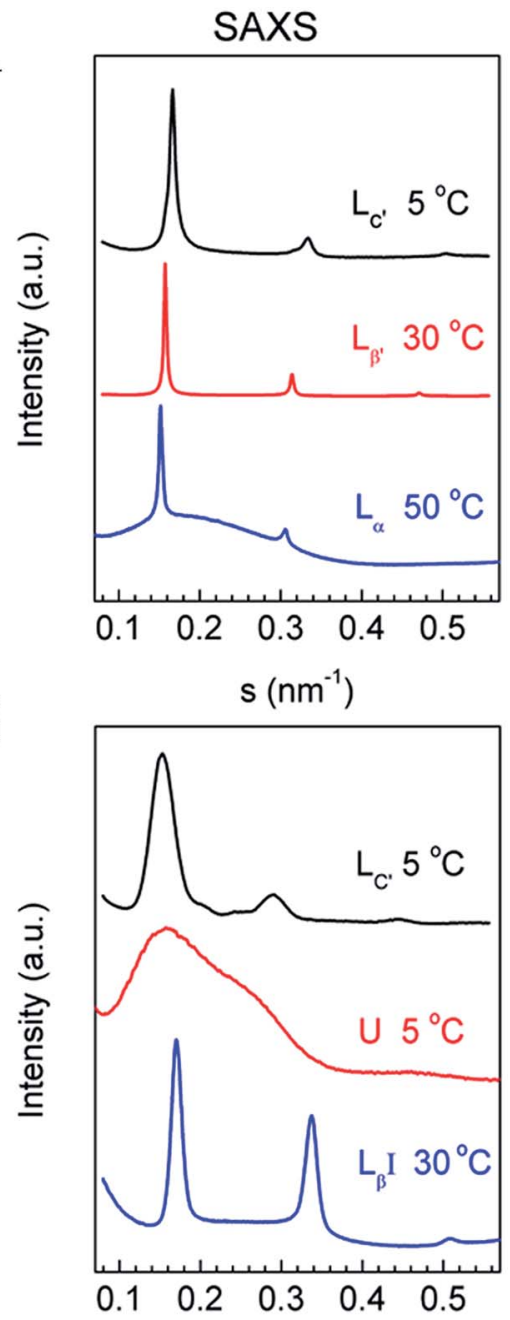

C

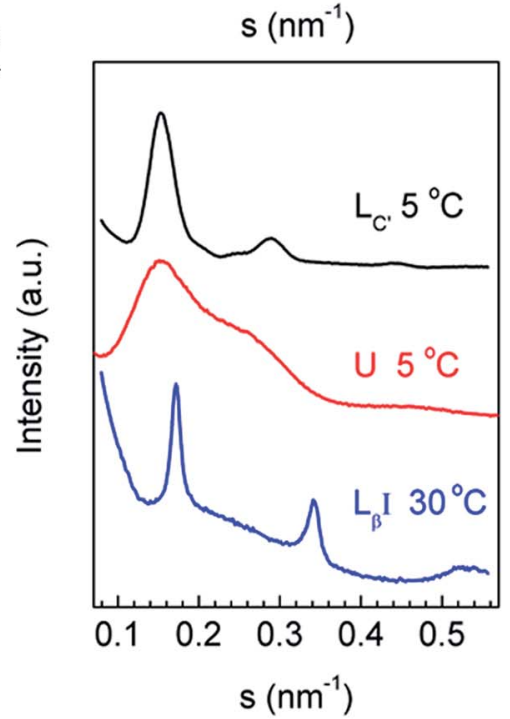

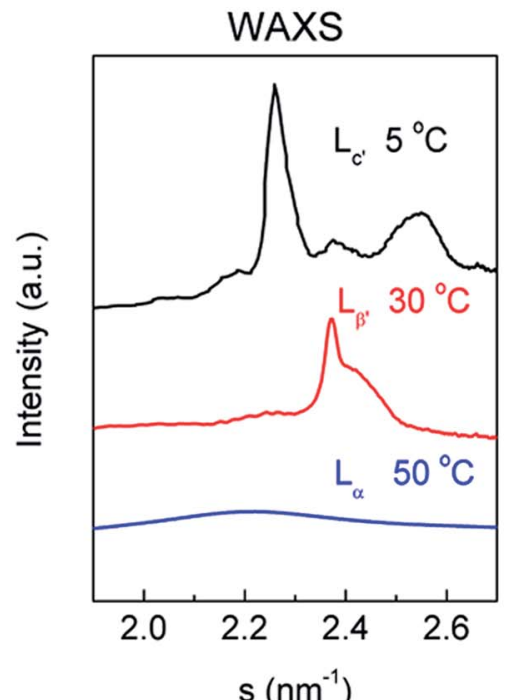
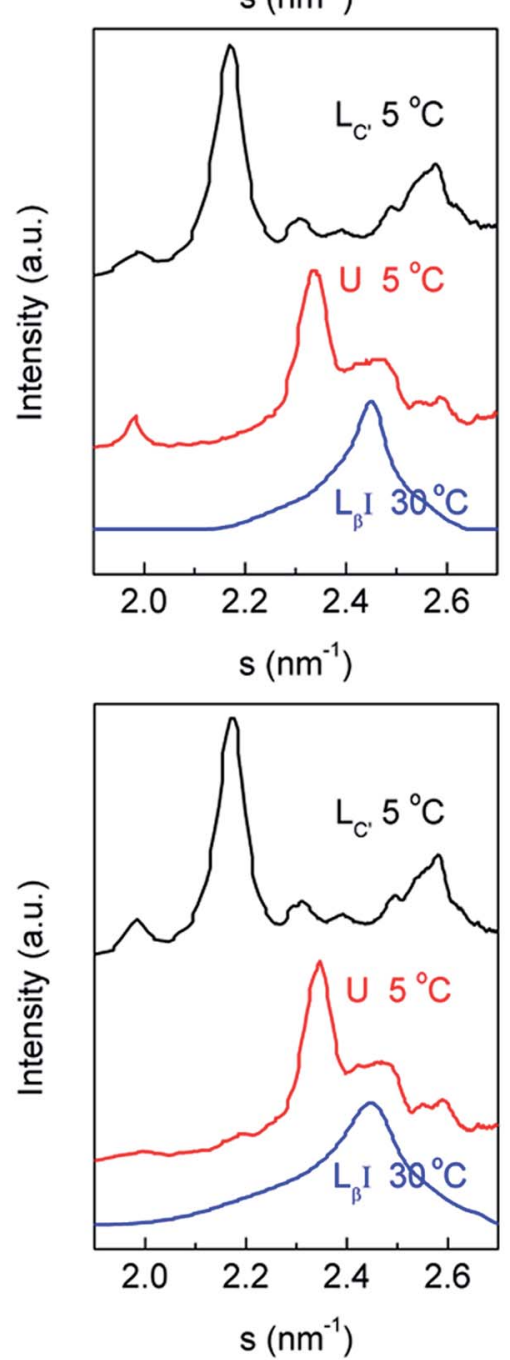

Fig. 2 SAXS (left) and WAXS (right) data of (A) DPPC, (B) DPPC-diC8PC ( $q=1.44)$, and (C) DPPC-diC8PC ( $q=1$ ). The corresponding phase states and temperatures are labeled above the curves.

direction of the bilayer surface normal for the phase. In the WAXS region, there are several peaks, showing a crystalline phase feature.
The submolecular details of each phase were characterized using FTIR experiments, and the results are shown in Fig. 3, while the FTIR peak assignments are shown in Table 1. Here we 
present results in 4 vibration regions, namely the $\mathrm{C}-\mathrm{H}$ stretching band $\left(3000-2800 \mathrm{~cm}^{-1}\right)$, the $\mathrm{C}=\mathrm{O}$ stretching band $(1800-$ $1650 \mathrm{~cm}^{-1}$ ), the $\mathrm{CH}_{2}$ scissoring band (1490-1440 $\left.\mathrm{cm}^{-1}\right)$, and the $\mathrm{PO}_{2}{ }^{-}$symmetric stretching band $\left(1140-1020 \mathrm{~cm}^{-1}\right)$. The samples we used here are the mixtures with $q=1.44$ and 1 , and the FTIR results for the two samples are similar. Four peaks are seen in the region of $3000-2800 \mathrm{~cm}^{-1}$, and they include a $\mathrm{CH}_{3}$ asymmetric stretching band (near $2950 \mathrm{~cm}^{-1}$ ), a $\mathrm{CH}_{2}$ asymmetric stretching band (near $2920 \mathrm{~cm}^{-1}$ ), a $\mathrm{CH}_{3}$ symmetric stretching band (near $2870 \mathrm{~cm}^{-1}$ ), and a $\mathrm{CH}_{2}$ symmetric stretching band (near $2850 \mathrm{~cm}^{-1}$ ), denoted as $\nu_{\text {as }} \mathrm{CH}_{3}, \nu_{\text {as }} \mathrm{CH}_{2}$, $\nu_{\mathrm{S}} \mathrm{CH}_{3}$, and $\nu_{\mathrm{s}} \mathrm{CH}_{2}$, respectively. The peak position changes in the $\mathrm{CH}_{2}$ stretching bands have been used frequently to follow the conformational order and to determine the relative amounts of trans and gauche conformers. ${ }^{32,33,59}$ When cooled from 60 to $30^{\circ} \mathrm{C}, \nu_{\text {as }} \mathrm{CH}_{2}$ and $\nu_{\mathrm{S}} \mathrm{CH}_{2}$ change from 2923 and 2854 $\mathrm{cm}^{-1}$ to 2919 and $2851 \mathrm{~cm}^{-1}$, respectively, indicating a decrease in gauche conformers when the lipids change from the liquid crystalline phase to the gel phase. For the $\mathrm{U}$ phase, the positions of $\nu_{\mathrm{as}} \mathrm{CH}_{2}$ and $\nu_{\mathrm{s}} \mathrm{CH}_{2}$ are 2918 and $2850 \mathrm{~cm}^{-1}$, while in the crystalline phase, they are 2916 and $2849 \mathrm{~cm}^{-1}$. The decrease in the wavenumber of the peak positions indicates an increase in trans conformers and a more ordered packing mode of the hydrocarbon chains.
Table 1 Wavenumbers $\left(\mathrm{cm}^{-1}\right)$ and assignments of FTIR absorption bands of DPPC-diC8PC binary mixtures with $q=1$ and 1.44

\begin{tabular}{lllll}
\hline $\mathrm{L}_{\alpha}\left(60{ }^{\circ} \mathrm{C}\right)$ & $\mathrm{L}_{\beta} \mathrm{I}\left(30^{\circ} \mathrm{C}\right)$ & $\mathrm{U}$ phase $\left(5{ }^{\circ} \mathrm{C}\right)$ & $\mathrm{L}_{\mathrm{c}^{\prime}}\left(5^{\circ} \mathrm{C}\right)$ & Assignment \\
\hline 2923 & 2919 & 2918 & 2916 & $\nu_{\mathrm{as}} \mathrm{CH}_{2}$ \\
2854 & 2851 & 2850 & 2849 & $\nu_{\mathrm{s}} \mathrm{CH}_{2}$ \\
1733 & 1735 & 1735 & 1733,1742 & $\nu \mathrm{C}=\mathrm{O}$ \\
1468 & 1468 & $1468 / 1469$ & 1472 & $\delta \mathrm{CH}_{2}$ \\
1088 & 1088 & 1087 & 1093 & $\nu_{\mathrm{s}} \mathrm{PO}_{2}^{-}$
\end{tabular}

The $\mathrm{CH}_{2}$ scissoring band $\left(\delta \mathrm{CH}_{2}\right)$ is often used to characterize the phase state of phospholipids through the lateral packing mode of the hydrocarbon chains. ${ }^{32,33,59}$ For the liquid crystalline phase, the gel phase, and the $\mathrm{U}$ phase, the positions of the $\mathrm{CH}_{2}$ scissoring band are all near $1468 / 1469 \mathrm{~cm}^{-1}$, signaling a hexagonal packing mode, and the slight change from 1468 $\mathrm{cm}^{-1}$ (gel phase) to $1469 \mathrm{~cm}^{-1}$ (U phase) may be interpreted as distortion of the hexagonal lattice. The $1472 \mathrm{~cm}^{-1} \mathrm{CH}_{2}$ scissoring band of the crystalline phase strongly suggests that the hydrocarbon chains are in a triclinic lattice. . $^{32,33,59}$

The $\mathrm{C}=\mathrm{O}$ stretching band of the liquid crystalline phase is a broad peak centered at $1733 \mathrm{~cm}^{-1}$, and as the lipids change to the gel phase, the peak becomes sharper and shifts to 1735
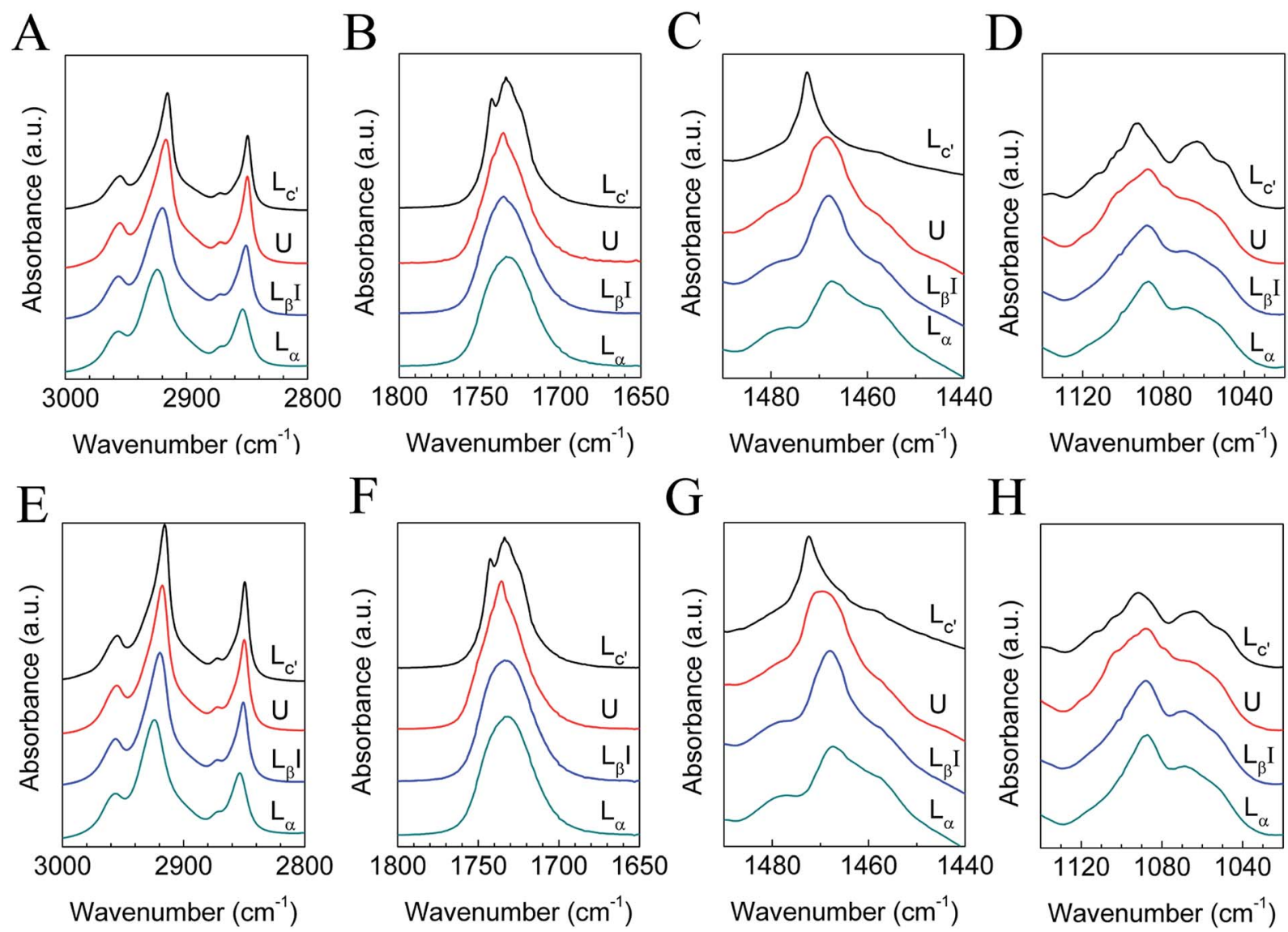

$\mathrm{H}$

Fig. 3 FTIR results of DPPC-diC8PC binary lipid mixtures with $q=1.44(A-D)$ and $1(E-H)$ in $H_{2} O(A, C-E, G$ and $H)$ or $D_{2} O(B$ and $F)$. The corresponding phase states are labeled by the curves. 
$\mathrm{cm}^{-1}$, due to the reduction in mobility in the interfacial region and dehydration of $\mathrm{C}=\mathrm{O}$. For the $\mathrm{U}$ phase, the peak becomes sharper than that of the gel phase, suggesting a further reduction in mobility in the interfacial region and dehydration of $\mathrm{C}=$ O. ${ }^{59-61}$ For the crystalline phase, the peak splits into two distinct peaks at 1733 and $1742 \mathrm{~cm}^{-1}$, which may correspond to the hydrogen-bonded and non-hydrogen-bonded $\mathrm{C}=\mathrm{O}$ species, respectively. From the data from the in situ SAXS experiment presented in Section 3.2, which clearly show a phase separation during the crystallization process, it seems that this assignment is reasonable. In the DPPC-rich phase, the lipids are in a lamellar crystalline phase and the $\mathrm{C}=\mathrm{O}$ group tends to form no hydrogen bond with $\mathrm{H}_{2} \mathrm{O}$, while in the dic8PC-rich phase, the lipids are in micelles and the $\mathrm{C}=\mathrm{O}$ group tends to form a hydrogen bond with $\mathrm{H}_{2} \mathrm{O}$. For this reason, the peaks at 1733 and $1742 \mathrm{~cm}^{-1}$ are assigned to dic8PC-rich micelles and the DPPC-rich crystalline phase, respectively. The marked shift from 1735 to $1742 \mathrm{~cm}^{-1}$ strongly suggests the dehydration of the interfacial region upon the phase transition from the gel to the crystalline phase, which is a common feature of the crystalline phase of lipids. ${ }^{31-33,59}$

In the $\mathrm{PO}_{2}{ }^{-}$symmetric stretching region, little change is seen between the liquid crystalline phase and the gel phase, indicating that the hydration situation is almost the same in these two phases. For the $\mathrm{U}$ phase and the crystalline phase, the $\mathrm{PO}_{2}{ }^{-}$ symmetric stretching band is different from the gel phase and the liquid crystalline phase, suggesting that the degree of hydration of the head group region changes in the two phases. ${ }^{32,59}$

\subsection{Kinetic properties of the crystalline and the $U$ phases}

The formation kinetics of the crystalline phases of all mixtures were studied using $T$-jump protocol, and the DSC results are shown in Fig. 4 and Table 2. For DPPC, after $24 \mathrm{~h}$ of nucleation at $-20{ }^{\circ} \mathrm{C}$, when we incubate the sample at $5{ }^{\circ} \mathrm{C}$ for 2 days, the peak area of the sub-transition is $7.9 \mathrm{~J} \mathrm{~g}^{-1}$, which increases to 18.7 $\mathrm{J} \mathrm{g}^{-1}$ if the incubation time at $5{ }^{\circ} \mathrm{C}$ increases to 4 days, close to the reported sub-transition enthalpy change $\left(19.2 \mathrm{~J} \mathrm{~g}^{-1}\right)$, indicating that most DPPC molecules transform into the crystalline phase. When we increase the nucleation time to $48 \mathrm{~h}, 2$ days of incubation at $5{ }^{\circ} \mathrm{C}$ is enough to generate the crystalline phase for almost all DPPC molecules, implying that the increase in the nucleation time can effectively reduce the crystal growth time. For this reason, we studied the influences of both the nucleation time and crystal growth time for samples with different compositions. For high- $q$ mixtures $(q=19,9$, and 4$)$, little or no crystalline phase can form even with a crystal growth time of 4 days if the nucleation time is $24 \mathrm{~h}$ (Fig. 4B-D). However, if the nucleation time is increased to $48 \mathrm{~h}$, they will form the crystalline phase even after 1 day of incubation at $5{ }^{\circ} \mathrm{C}$, suggesting that these mixtures form sufficient nuclei after $48 \mathrm{~h}$ of incubation at $-20{ }^{\circ} \mathrm{C}$ rather than $24 \mathrm{~h}$. Compared with DPPC, a longer nucleation time is required after adding diC8PC.

The situation is different for low- $q$ mixtures $(q=3,1.44$, and 1). For mixtures with $q=3$ (Fig. $4 \mathrm{E}$ ), after $24 \mathrm{~h}$ of incubation at $-20{ }^{\circ} \mathrm{C}$ and 1 day of incubation at $5{ }^{\circ} \mathrm{C}$, two peaks appeared in the DSC curve, and the positions of the two peaks are the same as the peak positions of the crystalline phase and the $\mathrm{U}$ phase, which is strong evidence of the coexistence of the crystalline phase and the $\mathrm{U}$ phase. When we prolonged the incubation time at $5{ }^{\circ} \mathrm{C}$, the peak of the $\mathrm{U}$ phase vanished, while the peak area of the sub-transition increased and finally reached a maximum, implying that the $\mathrm{U}$ phase converted to the crystalline phase during the incubation. This also means that the $U$ phase may act as a precursor phase in the crystallization process. For mixtures with $q=1.44$ (Fig. $4 \mathrm{~F}$ ), the peak of the $\mathrm{U}$ phase was not observed after $24 \mathrm{~h}$ of incubation at $-20^{\circ} \mathrm{C}$ and 1 day of incubation at $5{ }^{\circ} \mathrm{C}$. When the incubation time at $-20{ }^{\circ} \mathrm{C}$ was decreased to $0.5 \mathrm{~h}$, however, the coexistence of the $\mathrm{U}$ phase and the crystalline phase also emerged after 2 days of incubation at $5{ }^{\circ} \mathrm{C}$ and, finally, the $\mathrm{U}$ phase transformed into the crystalline phase after incubation at $5{ }^{\circ} \mathrm{C}$ for 4 days (data not shown). For mixtures with $q=1$ (Fig. $4 \mathrm{G}$ ), the crystallization process is similar to that for mixtures with $q=3$ and 1.44, but much faster.

In order to further unveil the formation mechanism of the crystalline phase, we performed an in situ SAXS experiment using the $T$-jump protocol for the $q=1$ mixture. This was possible because the crystallization process of the $q=1$ mixture treated with the $T$-jump protocol can be finished on a scale of hours. The results are shown in Fig. 5. The left panel of the figure is a series of time-resolved SAXS profiles and the right panel is an enlarged display of selected scattering profiles from the left panel (the thick lines). The sample was first heated to $60{ }^{\circ} \mathrm{C}$ in the test tube, allowing the lipid molecules to stay in the liquid crystalline phase, and then sealed in a sample cell at $10{ }^{\circ} \mathrm{C}$ to perform the $T$-jump protocol. At the starting point (10 ${ }^{\circ} \mathrm{C}$ ), the sample was in the gel phase $\left(\mathrm{L}_{\beta} \mathrm{I}\right)$. It was cooled to $-10{ }^{\circ} \mathrm{C}$ at a constant rate of $-10{ }^{\circ} \mathrm{C} \mathrm{min}{ }^{-1}$, transforming into the $\mathrm{U}$ phase. After incubation at $-10{ }^{\circ} \mathrm{C}$ for $12 \mathrm{~min}$, there appeared a number of sharp peaks, which can be classified into two groups (marked with a and b). Both are identified as lamellar phases with repeat spacings of 5.92 and $3.88 \mathrm{~nm}$. The former is close to the spacing of DPPC and is assigned as the DPPC-rich phase, and the latter is assigned as the diC8PC-rich phase. During the incubation at $-10{ }^{\circ} \mathrm{C}$, the two lamellar structures were found to be stable. Then, the sample was heated from $-10{ }^{\circ} \mathrm{C}$ to $10^{\circ} \mathrm{C}$ at a constant rate of $1{ }^{\circ} \mathrm{C} \mathrm{min}^{-1}$. Clearly noticeable are the shifts of all the diffraction peaks towards a lower angle, indicating increases in the repeating spacings of both lamellar structures. At about $0{ }^{\circ} \mathrm{C}$, the "b" phase disappeared. The remaining "a" phase transforms into the lamellar crystalline phase.

Based on the data, we conclude that the low- $q$ mixtures crystallize via the $\mathrm{U}$ phase; in other words, the $\mathrm{U}$ phase is a precursor of the lamellar-crystalline phase ("a" phase in Fig. 5) for mixtures with lower $q$ values. The dic8PC-rich phase ("b" phase in Fig. 5) that emerged during the crystallization process transforms into a micelle phase upon heating, corresponding to the vanishing of the scattering peaks at $s=0.258$ and 0.516 $\mathrm{nm}^{-1}$. This is in line with published literature, which reported a micelle structure of diC8PC in $\mathrm{H}_{2} \mathrm{O}$ at room temperature. ${ }^{62}$ It is worth noting that the protocol used here is not the exact $T$-jump protocol described in Section 2.2. The nucleation temperature used here is $-10{ }^{\circ} \mathrm{C}$ instead of $-20{ }^{\circ} \mathrm{C}$, and the crystal growth 


\section{A}

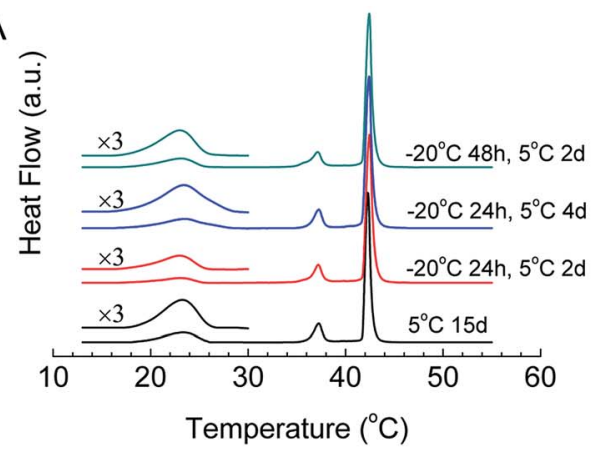

C

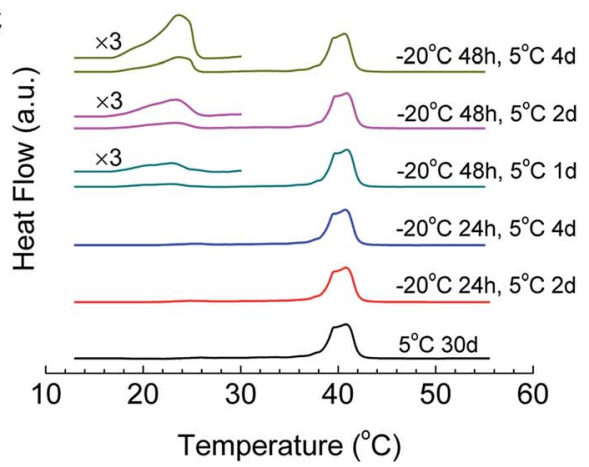

E

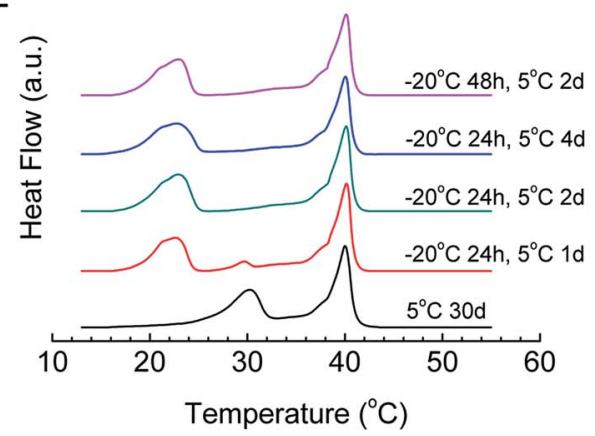

G

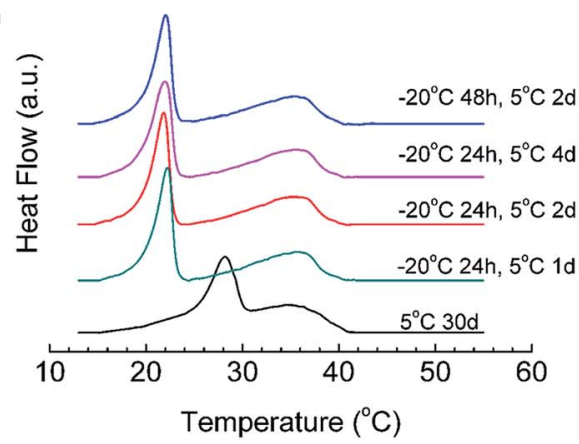

$\mathrm{B}$

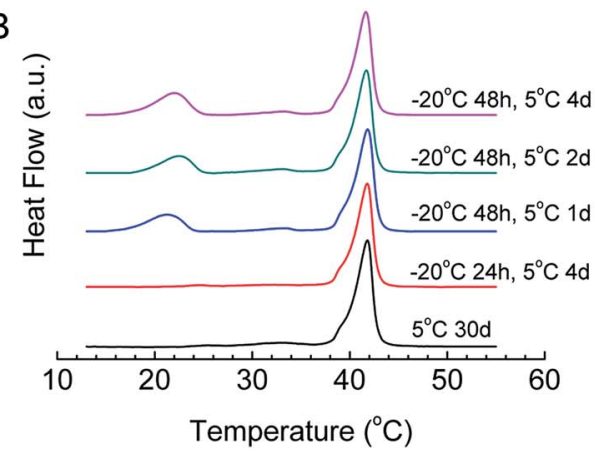

D

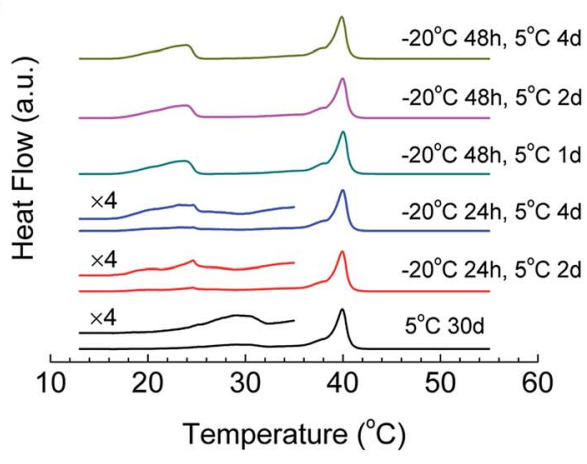

$\mathrm{F}$

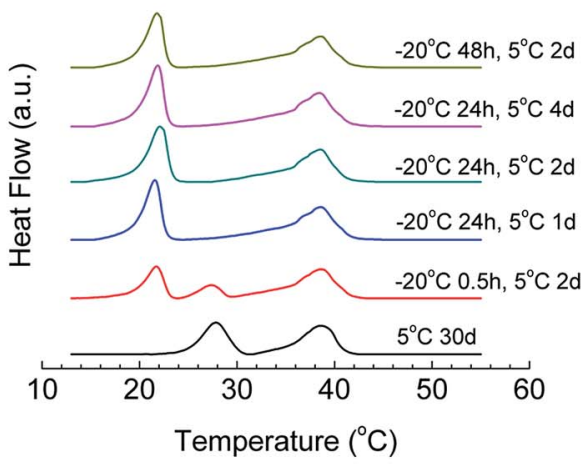

Fig. 4 DSC results of DPPC-diC8PC binary lipid mixtures dispersed in water after incubation at $-20{ }^{\circ} \mathrm{C}$ and $5^{\circ} \mathrm{C}$ for different periods of time, as indicated by the curves. The $q$ values are (A) $\infty,(B) 19,(C) 9$, (D) $4,(E) 3,(F) 1.44$, and (G) 1.

temperature is $10{ }^{\circ} \mathrm{C}$ instead of $5{ }^{\circ} \mathrm{C}$. This change was made for the convenience of SAXS-WAXS measurements. We have run a DSC experiment using this protocol, and the results (Fig. S1†) support the general conclusions we achieved using the standard protocol.
The kinetic properties of the $U$ phase under isothermal conditions with $q=1.44$ and 1 were also studied, and the DSC results are shown in Fig. 6 . The mixtures had been incubated at $5{ }^{\circ} \mathrm{C}$ for 7,30 , and 60 days before DSC scanning. The thermograms indicate that both mixtures stayed in the gel phase after 7 
Table 2 Enthalpy data $\left(\mathrm{J} \mathrm{g}^{-1}\right)$ of the sub-transition ${ }^{\mathrm{a}}$ and the $\mathrm{U}$-gel phase transition ${ }^{\mathrm{b}}$ of the DPPC-diC $8 \mathrm{PC}$ binary mixtures at various $q$ values $(q=$ $\infty$ is pure DPPC in $\mathrm{H}_{2} \mathrm{O}$ )

\begin{tabular}{|c|c|c|c|c|c|c|c|}
\hline Sample treatment & $q=\infty$ & 19 & 9 & 4 & 3 & 1.44 & 1 \\
\hline $30 \mathrm{~d}$ at $5{ }^{\circ} \mathrm{C}($ for DPPC, $15 \mathrm{~d})$ & $18.3^{\mathrm{a}}$ & $0^{\mathrm{b}}$ & $0^{\mathrm{b}}$ & small $^{\mathrm{b}}$ & $15.3^{\mathrm{b}}$ & $11.3^{\mathrm{b}}$ & $9.5^{\mathrm{b}}$ \\
\hline $24 \mathrm{~h}$ at $-20^{\circ} \mathrm{C}$ then $1 \mathrm{~d}$ at $5{ }^{\circ} \mathrm{C}$ & & & & & $18.1^{\mathrm{a}}$ & $15.0^{\mathrm{a}}$ & $12.1^{\mathrm{a}}$ \\
\hline $24 \mathrm{~h}$ at $-20^{\circ} \mathrm{C}$ then $2 \mathrm{~d}$ at $5{ }^{\circ} \mathrm{C}$ & $7.9^{\mathrm{a}}$ & & $0^{\mathrm{a}}$ & small $^{\mathrm{a}}$ & $20.0^{\mathrm{a}}$ & $15.0^{\mathrm{a}}$ & $13.0^{\mathrm{a}}$ \\
\hline $24 \mathrm{~h}$ at $-20{ }^{\circ} \mathrm{C}$ then $4 \mathrm{~d}$ at $5{ }^{\circ} \mathrm{C}$ & $18.7^{\mathrm{a}}$ & $0^{\mathrm{a}}$ & $0^{\mathrm{a}}$ & small $^{\mathrm{a}}$ & $21.6^{\mathrm{a}}$ & $15.5^{\mathrm{a}}$ & $12.1^{\mathrm{a}}$ \\
\hline $48 \mathrm{~h}$ at $-20^{\circ} \mathrm{C}$ then $1 \mathrm{~d}$ at $5{ }^{\circ} \mathrm{C}$ & & $12.7^{\mathrm{a}}$ & $6.0^{\mathrm{a}}$ & $23.4^{\mathrm{a}}$ & & & \\
\hline $48 \mathrm{~h}$ at $-20^{\circ} \mathrm{C}$ then $2 \mathrm{~d}$ at $5{ }^{\circ} \mathrm{C}$ & $16.2^{\mathrm{a}}$ & $12.5^{\mathrm{a}}$ & $12.4^{\mathrm{a}}$ & $22.7^{\mathrm{a}}$ & $21.4^{\mathrm{a}}$ & $14.4^{\mathrm{a}}$ & $12.4^{\mathrm{a}}$ \\
\hline $48 \mathrm{~h}$ at $-20^{\circ} \mathrm{C}$ then $4 \mathrm{~d}$ at $5^{\circ} \mathrm{C}$ & & $15.4^{\mathrm{a}}$ & $26.0^{\mathrm{a}}$ & $23.4^{\mathrm{a}}$ & & & \\
\hline
\end{tabular}

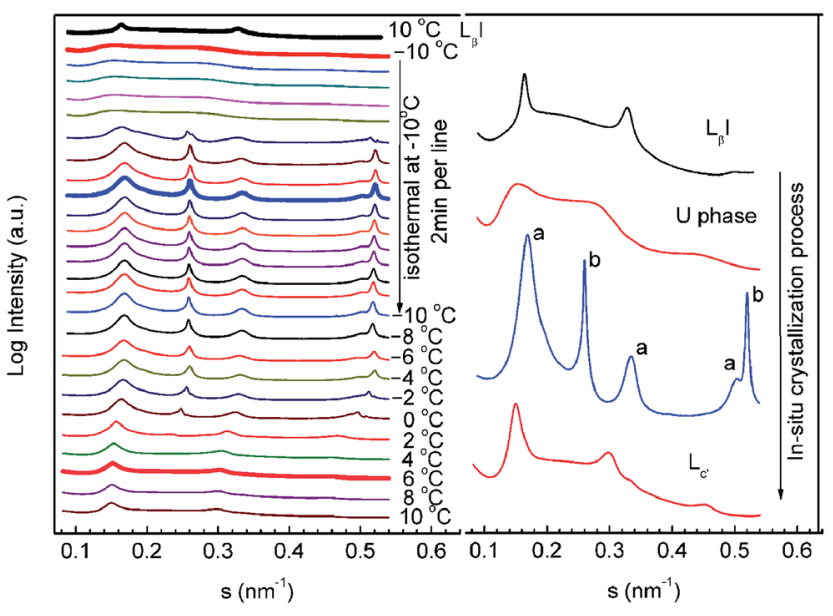

Fig. 5 Time-resolved in situ SAXS results for DPPC-diC8PC binary lipid mixture $(q=1)$ during the crystallization process. Left: the sample was cooled from 10 to $-10{ }^{\circ} \mathrm{C}$ at $10{ }^{\circ} \mathrm{C} \mathrm{min}{ }^{-1}$, incubated at this temperature for $30 \mathrm{~min}$, and then heated to $10^{\circ} \mathrm{C}$ at $1{ }^{\circ} \mathrm{C} \mathrm{min}^{-1}$. Right: enlarged display of selected scattering profiles (thick line) from the left panel.

days of incubation, while they formed the $\mathrm{U}$ phase after 30 days of incubation at $5{ }^{\circ} \mathrm{C}$. The enthalpy changes of the $\mathrm{U}$ phase to the gel phase after 30 days of incubation at $5{ }^{\circ} \mathrm{C}$ are $11.3 \mathrm{~J} \mathrm{~g}^{-1}$ and $9.5 \mathrm{~J} \mathrm{~g}^{-1}$ for the mixtures with $q=1.44$ and 1 , respectively, reaching the maxima. This suggests that after 30 days of incubation at $5{ }^{\circ} \mathrm{C}$, the samples transformed completely from the lamellar gel to the U-phase state. Finally, the samples transformed to the crystalline phase after another 30 days of incubation at $5{ }^{\circ} \mathrm{C}$, and the enthalpy changes of the subtransition are $15.3 \mathrm{~J} \mathrm{~g}^{-1}$ and $11.5 \mathrm{~J} \mathrm{~g}^{-1}$ for the mixtures with $q$ $=1.44$ and 1 , respectively, close to the enthalpy data of the subtransition obtained by the T-jump protocol, shown in Table 2 . This indicates that most molecules in the samples were in the crystalline state after 60 days of incubation at $5{ }^{\circ} \mathrm{C}$. Clearly, during isothermal incubation at $5{ }^{\circ} \mathrm{C}$, the gel phase first changed to the $\mathrm{U}$ phase and then converted to the crystalline phase after prolonged incubation. This is further strong evidence that the $\mathrm{U}$ phase acts as a precursor phase during the crystallization process.

\section{Conclusion}

In this work, we have systematically studied the phase behavior of the DPPC-diC8PC system using DSC, SAXS-WAXS, and FTIR. Firstly, we studied the phase behavior using both the $T$-jump protocol and the isothermal protocol, and found that at both high and low $q$, a lamellar crystalline phase $\left(\mathrm{L}_{\mathrm{c}^{\prime}}\right)$ enriched in DPPC was the most stable phase at $5{ }^{\circ} \mathrm{C}$. Formation of the crystalline phase accompanies segregation of a diC8PCenriched micelle phase. Interestingly, for low- $q$ mixtures $(1 \leq$ $q \leq 4$ ), a metastable phase, named the U phase, was observed. The structural features of the $\mathrm{U}$ and crystalline phases were characterized using SAXS-WAXS and FTIR. The crystalline phase is a lamellar structure with a triclinic packing mode of the hydrocarbon chains, while the $\mathrm{U}$ phase is found to lose the longrange order in the bilayer normal direction but gains a different
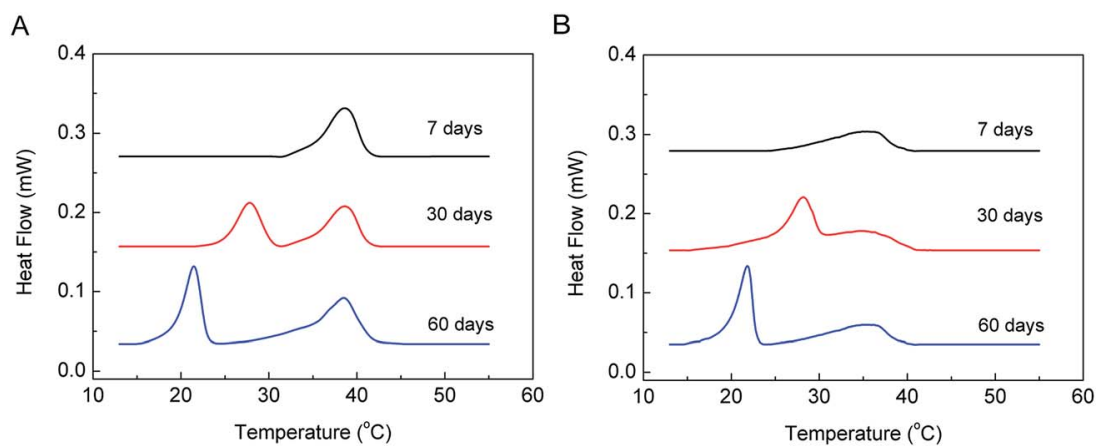

Fig. 6 DSC results of DPPC-diC8PC binary lipid mixtures dispersed in $\mathrm{H}_{2} \mathrm{O}$ using isothermal protocol after incubation at $5{ }^{\circ} \mathrm{C}$ for different periods of time, as indicated by the curves. The DPPC/diC8PC molar ratios are (A) 1.44 and (B) 1. 
"crystalline phase-like" hydrocarbon chain packing mode. Secondly, we studied the formation kinetic properties of the $U$ and crystalline phases and found that, for high- $q$ mixtures, more time is needed at $-20{ }^{\circ} \mathrm{C}$ to form nuclei, and thus diC8PC acts as an inhibitor for the crystallization of lipids, while for low- $q$ mixtures, a much faster crystallization rate was recorded via the intermediate $\mathrm{U}$ phase. Upon incubation at low temperatures, the $\mathrm{U}$ phase separates into a lamellar DPPC-enriched phase and a lamellar diC8PC-enriched phase at $-10{ }^{\circ} \mathrm{C}$, and finally transforms into a lamellar crystalline phase $\left(\mathrm{L}_{\mathrm{c}^{\prime}}\right)$ enriched in DPPC, along with a diC8PC-enriched micelle phase above $0{ }^{\circ} \mathrm{C}$. The present work deepens our understanding of the lipid crystallization process and will also provide helpful knowledge of lipid binary mixtures composed of long- and short-chain lipids, which are often applied in membrane protein studies.

\section{Acknowledgements}

This work was supported by a grant from the National Natural Science Foundation of China (21273130). The SAXS and WAXS data were collected at the Beamline 1W2A of the Beijing Synchrotron Radiation Facility (BSRF) with the assistance of Prof. Zhong-Hua Wu (Institute of High Energy Physics) and the station scientists.

\section{Notes and references}

1 C. R. Sanders and J. H. Prestegard, Biophys. J., 1990, 58, 447.

2 C. R. Sanders and J. P. Schwonek, Biochemistry, 1992, 31, 8898.

3 U. H. N. Dürr, R. Soong and A. Ramamoorthy, Prog. Nucl. Magn. Reson. Spectrosc., 2013, 69, 1.

4 U. H. N. Dürr, M. Gildenberg and A. Ramamoorthy, Chem. Rev., 2012, 112, 6054.

5 I. Marcotte and M. Auger, Concepts Magn. Reson., 2005, 24, 17.

6 D. E. Warschawski, A. A. Arnold, M. Beaugrand, A. Gravel, É. Chartrand and I. Marcotte, Biochim. Biophys. Acta, 2011, 1808, 1957.

7 U. H. N. Dürr, L. Waskell and A. Ramamoorthy, Biochim. Biophys. Acta, 2007, 1768, 3235.

8 Y. Liu, R. A. Kahn and J. H. Prestegard, Nat. Struct. Mol. Biol., 2010, 17, 876.

9 J. A. Losonczi, F. Tian and J. H. Prestegard, Biochemistry, 2000, 39, 3804.

10 É. Chartrand, A. A. Arnold, A. Gravel, S. Jenna and I. Marcotte, Biochim. Biophys. Acta, 2010, 1798, 1651.

11 C. B. Kang and Q. Li, Curr. Opin. Chem. Biol., 2011, 15, 560. 12 M. Caffrey, J. Struct. Biol., 2003, 142, 108.

13 S. Faham and J. U. Bowie, J. Mol. Biol., 2002, 316, 1.

14 S. Faham, R. Ujwal, J. Abramson and J. U. Bowie, Curr. Top. Membr., 2009, 63, 109.

15 L. C. Johansson, A. B. Wöhri, G. Katona, S. Engström and R. Neutze, Curr. Opin. Struct. Biol., 2009, 19, 372.

16 H. Wang, J. Elferich and E. Gouaux, Nat. Struct. Mol. Biol., 2012, 19, 212.
17 H. Biverståhl, J. Lind, A. Bodor and L. Mäler, Biochim. Biophys. Acta, 2009, 1788, 1976.

18 W. Surya, Y. Li, O. Millet, T. Diercks and J. Torres, PLoS One, 2013, 8, e74281.

19 K. T. Nguyen, R. Soong, S. C. Im, L. Waskell, A. Ramamoorthy and Z. Chen, J. Am. Chem. Soc., 2010, 132, 15112.

20 I. Marcotte, A. Bélanger and M. Auger, Chem. Phys. Lipids, 2006, 139, 137.

21 S. Ye, H. Li, W. Yang and Y. Luo, J. Am. Chem. Soc., 2014, 136, 1206.

22 C. Kang, C. Tian, F. D. Sönnichsen, J. A. Smith, J. Meiler, A. L. George Jr, C. G. Vanoye, H. J. Kim and C. R. Sanders, Biochemistry, 2008, 47, 7999.

23 L. Lin, X. Wang, Y. Guo, K. Ren, X. Li, L. Jing, X. Yue, Q. Zhang and Z. Dai, RSC Adv., 2016, 6, 79811.

24 Y. Song, R. M. Dorin, R. M. Garcia, Y. B. Jiang, H. Wang, P. Li, Y. Qiu, F. van Swol, J. E. Miller and J. A. Shelnutt, J. Am. Chem. Soc., 2008, 130, 12602.

25 R. M. Garcia, Y. Song, R. M. Dorin, H. Wang, A. M. Moreno, Y. B. Jiang, Y. Tian, Y. Qiu, C. J. Medforth, E. N. Coker, F. van Swol, J. E. Miller and J. A. Shelnutt, Phys. Chem. Chem. Phys., 2011, 13, 4846.

26 R. Ujwal, D. Cascio, J. P. Colletier, S. Faham, J. Zhang, L. Toro, P. Ping and J. Abramson, Proc. Natl. Acad. Sci. U. S. A., 2008, 105, 17742.

27 K. Yamamoto, R. Soong and A. Ramamoorthy, Langmuir, 2009, 25, 7010.

28 Z. W. Yu, N. M. Tsvetkova, L. I. Tsonev and P. J. Quinn, Biochim. Biophys. Acta, 1995, 1237, 135.

29 L. Chen, Z. W. Yu and P. J. Quinn, Biophys. Chem., 2001, 89, 231.

30 R. G. Wu, L. Chen, Z. W. Yu and P. J. Quinn, Biochim. Biophys. Acta, 2006, 1758, 764.

31 F. G. Wu, L. Chen and Z. W. Yu, J. Phys. Chem. B, 2009, 113, 869.

32 F. G. Wu, Q. Jia, R. G. Wu and Z. W. Yu, J. Phys. Chem. B, 2011, 115, 8559.

33 F. G. Wu, H. Y. Sun, Y. Zhou, R. G. Wu and Z. W. Yu, RSC $A d v .$, 2014, 4, 51171.

34 F. G. Wu, H. Y. Sun, Y. Zhou, G. Deng and Z. W. Yu, RSC Adv., 2015, 5, 726.

35 S. C. Chen, J. M. Sturtevant and B. J. Gaffney, Proc. Natl. Acad. Sci. U. S. A., 1980, 77, 5060.

36 L. Finegold and M. A. Singer, Chem. Phys. Lipids, 1984, 35, 291.

37 L. Finegold and M. A. Singer, Biochim. Biophys. Acta, 1986, $855,417$.

38 S. Tristram-Nagle, M. C. Wiener, C. P. Yang and J. F. Nagle, Biochemistry, 1987, 26, 4288.

39 R. N. Lewis, N. Mak and R. N. McElhaney, Biochemistry, 1987, 26, 6118.

40 R. Lewis and R. N. McElhaney, Biochemistry, 1990, 29, 7946. 41 R. N. Lewis and R. N. McElhaney, Biophys. J., 1992, 61, 63.

42 J. Katsaras, V. A. Raghunathan, E. J. Dufourc and J. Dufourcq, Biochemistry, 1995, 34, 4684. 
43 R. Koynova, B. G. Tenchov, S. Todinova and P. J. Quinn, Biophys. J., 1995, 68, 2370.

44 B. Tenchov, R. Koynova and G. Rapp, Biophys. J., 2001, 80, 1873.

45 H. H. Chang, R. K. Bhagat, R. Tran and P. Dea, J. Phys. Chem. $B, 2006,110,22192$.

46 S. Tristram-Nagle, R. M. Suter, W. J. Sun and J. F. Nagle, Biochim. Biophys. Acta, 1994, 1191, 14.

47 E. B. Sirota and A. B. Herhold, Science, 1999, 283, 529.

48 Y. Shinohara, N. Kawasaki, S. Ueno, I. Kobayashi, M. Nakajima and Y. Amemiya, Phys. Rev. Lett., 2005, 94, 097801.

49 Z. Li, Z. Wu, G. Mo, X. Xing and P. Liu, Instrum. Sci. Technol., 2014, 42, 128.

50 Y. Wei and Z. Li, Instrum. Sci. Technol., 2016, 44, 1.

51 J. Katsaras, J. Phys. Chem., 1995, 99, 4141.
52 M. J. Ruocco and G. G. Shipley, Biochim. Biophys. Acta, 1982, 684, 59.

53 M. J. Ruocco and G. G. Shipley, Biochim. Biophys. Acta, 1982, 691, 309.

54 H. Takahashi, K. Hatta and I. Hatta, J. Phys. II, 1996, 6, 1657. 55 A. Tardieu, V. Luzzati and F. C. Reman, J. Mol. Biol., 1973, 75, 711.

56 G. W. Brady and D. B. Fein, Biochim. Biophys. Acta, 1977, 464, 249.

57 Z. W. Yu and P. J. Quinn, Biophys. J., 1995, 69, 1456.

58 V. A. Raghunathan and J. Katsaras, Phys. Rev. Lett., 1995, 74, 4456.

59 A. Dopico, Methods in Membrane Lipids, Human Press, Totowa, 2007.

60 F. G. Wu, J. J. Luo and Z. W. Yu, Langmuir, 2010, 26, 12777. 61 E. A. Disalvo and M. A. Frias, Langmuir, 2013, 29, 6969. 62 H. Hauser, Biochim. Biophys. Acta, 2000, 1508, 164. 